\title{
ANALISIS HUMAN ERROR PADA OPERATOR ENGINE ROOM PT. ADEI PLANTATION \& INDUSTRY DENGAN METODE HUMAN ERROR ASSESMENT AND REDUCTION TECHNIQUE (HEART)
}

\author{
Monica Widiyawati \\ Program Studi Teknik Industri, Fakultas Teknik, Universitas Muhammadiyah Riau \\ Jalan Tuanku Tambusai Ujung, Kecamatan Tampan, Kelurahan Delima, Kota Pekanbaru, Riau 28291 \\ E-mail: Monicawidiya27@gmail.com
}

\begin{abstract}
PT. Adei Plantation \& Industry is a plantation company that operates on plantation and palm oil industries. CPO production of palm oil is needed for consumption, which is run by power stations and for distribution (engine room) involving operators. Since january to june 2020, there is a sudden shutdown in the work of research for the analysis of human errors in the engine room using HEART method. The HEART method is used to evaluate the possibility of human error in all the work and to count the erros in various mays. Data management shows that there are 4 task operators that are common to the plant turbine engines and 6 task forces on the genertor. The highest HEP rating on the turbin engine was 0,6528 with the greatest error potential for task 3, the turbine engine operation. For the highest HEP value on the generator engine is 3,1759 with an error potential in task 5.
\end{abstract}

Keywords : Human Error, Human Error Assesment And Reduction Technique (HEART), HEP

\begin{abstract}
Abstrak
PT. Adei Plantation \& Industry merupakan perusahaan yang bergerak di bidang perkebunan dan industri kelapa sawit. Dalam pengolahan kelapa sawit menjadi crude palm oil (CPO) memerlukan konsumsi energi listrik yang dikelola di stasiun pembangkit dan pendistribusian (engine room) yang melibatkan operator. Sejak bulan januari sampai dengan bulan juni 2020 listrik mengalami mati secara mendadak, oleh karena itu peneliti melakukan analisis human error pada operator engine room menggunakan metode HEART. Metode HEART untuk mengevaluasi kemungkinan kesalahan manusia yang terjadi diseluruh penyelesaian tugas dan menghitung probabilitas error. Hasil pengolahan data menunjukkan bahwa terdapat 4 task kesalahan operator yang sering terjadi pada mesin pembangkit yaitu mesin turbin dan 6 task kesalahan operator pada mesin genset. Hasil perhitungan nilai HEP yang tertinggi pada mesin turbin adalah 0,6528 dengan potensi error terbesar terjadi pada task 3 yaitu pengoperasin mesin turbin. Untuk nilai HEP tertinggi pada mesin genset adalah 3,1759 dengan potensi error terjadi pada task 5.
\end{abstract}

Kata Kunci : Human Error, Human Error Assesment And Reduction Technique (HEART), HEP

\section{Pendahuluan}

Perubahan industri dari abad ke abad semakin tampak maju, seiring dengan perubahan teknologi dan kebutuhan akan produk dari industri yang berfungsi untuk kelangsungan hidup orang banyak. Proses pada industri terjadi beberapa kegiatan yang cenderung error. Dalam hal ini manusia ikut berperan aktif dalam melaksanakan setiap aktivitas. Manusia berpotensi untuk melakukan kesalahan kerja (human error) dalam melaksanakan aktivitas, karena manusia memiliki keterbatasan yang dapat menyebabkan ketidaklancarannya suatu aktivitas dalam setiap proses.

Menurut Dhillon, B, 2007, kesalahan manusia dijelaskan seperti kelalaian dalam menyelesaikan pekerjaan yang khusus (mengerjakan pekerjaan yang terlarang) yang dapat menyebabkan gangguan tentang agenda kerja atau mengakibatkan kehancuran peralatan dan barang lainnya. Penilaian prestasi kerja sangat penting untuk dikerjakan dengan maksud 
dapat menurunkan taraf kegagalan kerja. Maka dari itu, perlu diperhitungkan untuk menurunkan taraf kegagalan kerja yang dapat terjadi oleh pekerja saat mengerjakan kegiatan kerjanya dengan mengidentifikasi kesalahan yang ada.

PT. Adei Plantation \& Industry adalah perusahaan yang bergerak dikeahlian perkebunan dan industri buah kelapa sawit yang berada di daerah Kabupaten Pelalawan, Riau. Dalam melaksanakan aktivitas operasi pengerjaan buah kelapa sawit menjadi crude palm oil (CPO) melewati semua tahapan yang membutuhkan pemakaian tenaga listrik, tenaga listrik yang diperlukan dikelola di stasiun pembangkit dan pendistribusian daya listrik ke semua beban distribusi listrik baik processing maupun dosmetik yang disebut engine room. Daya pembangkit yang dimiliki oleh PT. Adei Plantation \& Industry adalah sebesar $1.200 \mathrm{kWh}$.

Pada engine room terdapat main switch board yaitu sebagai kontrol panel yang mengarahkan sumber listrik dari satu sumber ke sumber yang lain. Selain alat tersebut, terdapat 2 mesin turbin dan 3 mesin genset yang merupakan alat pembangkit listrik untuk menghasilkan tenaga listrik. Jumlah pekerja pada stasiun engine room berjumlah 3 orang operator yang bekerja selama 24 jam, setiap operator bekerja selama 8 jam.

Dengan jumlah operator yang setiap shift hanya 1 orang jadi operator kewalahan dalam mengontrol satu persatu mesin-mesin tersebut, mulai dari pemeriksaan hour meter, pemeriksaan oli-air, dan pembersihan setiap mesin, sehingga sering terjadi listrik mati mendadak. Listrik mati diakibatkan karena pengoperasian yang tidak sesuai dengan SOP, kelebihan kapasitas pada beban mesin karena operator kurang memperhatikan hour meter dan lambat bergerak untuk memeriksa setiap tekenan pada mesin, sehingga aktivitas langsung terhenti. Aktivitas terhenti selama lebih kurang 30 menit sehingga dapat menyita waktu proses produksi dan aktivitas lainnya. Sehingga dengan terjadinya listrik dapat menyebabkan kerugian pada perusahaan. Kerugian yang dialami oleh perusahaan seperti jumlah produksi crude palm oil (CPO) menjadi menurun, kerjaan karyawan menjadi menumpuk, pendapatan perusahaan jadi berkurang, pengeluaran biaya terlalu tinggi untuk perbaikan mesin. Berikut data listrik mati dan jumlah produksi pada bulan januari-juni 2020:

Tabel 1. Data Listrik Mati dan Jumlah Produksi Pada Januari-Juni 2020 :

\begin{tabular}{|c|l|c|c|c|}
\hline$N_{0}$ & $\begin{array}{c}\text { Waktu } \\
\text { (bulan) }\end{array}$ & $\begin{array}{c}\text { ListrikMati } \\
\text { Keseluruhan } \\
\text { (jam) }\end{array}$ & $\begin{array}{c}\text { Listrik Mati } \\
\text { Karena Human } \\
\text { Error(Jam) }\end{array}$ & $\begin{array}{c}\text { Jumlah Produksi } \\
\text { (ton/bulan) }\end{array}$ \\
\hline 1 & Januari & 5 & 2,5 & 30.265 \\
\hline 2 & Februan & 3 & 2 & 25.900 \\
\hline 3 & Maret & 4 & 2,5 & 30.265 \\
\hline 4 & April & 5 & 2,5 & 29.000 \\
\hline 5 & Mai & 4 & 2 & 24.895 \\
\hline 6 & Juni & 5 & 2,5 & 30.285 \\
\hline
\end{tabular}

Berlandaskan pada tabel 1.1 bahwa dari bulan januari sampai dengan bulan juni 2020 data listrik mati secara keseluruhan paling lama selama 5 jam dan listrik mati yang disebabkan human error rata-rata paling lama 2.5 jam. Sehingga jumlah produksi biasanya berkapasitas 90 ton/jam pada jam kerja produksi selama 11 jam saat ini berkurangnya jumlah produksi akibat listrik mati. Berdasarkan latar belakang masalah ini peneliti ingin melakukan perbaikan pada cara kerja operator dengan mengharapkan perubahan yang positif yaitu dengan mengetahui tingkat probabilitas human error pada operator engineroom.

Kesalahan manusia (human error) ditentukan seperti ketetapan atau perbuatan manusia yang tidak benar untuk menurunkan daya guna, keamanan atau kinerja (Sanders \& McCormick, 1993) [1]. Kelalaian yang disebabkan oleh manusia membuat pengaruh minus terhadap kinerja perusahaan. Menurut Meister, 20\%$50 \%$ kesalahan yang timbul pada sistem karena human error. Menurut Meister dalam Soesanto (2010) [2]. Kesalahan manusia terjadi karena penyebab dalam diri seseorang maupun penyebab dari luar diri seseorang (Wahyu, 2015: 110-115) [3]. Khilaf dan lupa ialah kegagalan di dalam pelaksanaan pekerjaan, dimana slips dapat diamati, sedangkan lapses merupakan kesalahan yang mengakibatkan ingatan dimana yang tahu adalah orang yang mengalami sendiri (Winarsunu, 2008: 35) [4]. Menurut Sanders dan Mc. Cormick (1993) [5], frekuensi dan konsekuensi dari human error dapat dikurangi dengan cara :

1. Dalam pemilihan karyawan (seleksi) dilakuka dengan mengetahui kemampuan yang sesuai dengan pekerjaan akan mengurangi human error, yaitu kemampuan motorik dan intelektual.

2. Pelatihan pada kegagalan dapat diperbaiki dengan pelatihan yang baik terhadap karyawan.

3. Perancangan desain mesin, langkah kerja, dan lingkungan dapat meningkatkan performa dari karyawan.

Menurut Dhillon pada tahun 2005 [6], reliability dapat didefinisikan sebagai probabilitas sebuah benda melaksanakan tujuan spesifiknya dengan memuaskan pada waktu dan kondisi yang telah ditetapkan. Secara kuantitatif, reliabilitas menetapkan probabilitas bahwa tidak ada interupsi operasional akan terjadi 
selama interval waktu yang ditentukan (Birolini, 2017: 2) [7]. HRA adalah kumpulan metode yang dipakai untuk menilai dan mengetahui kejadian human error. Hollnagel (2005) [8] menjelasakan ada 3 fungsi dari HRA yaitu :

1. Mengetahui masalah yang terjadi

2. Menentukan seperti apa masalah bisa terjadi

3. Menentukan bagaimana untuk mengurangi masalah yang terjadi

Human Reliability memiliki 72 metode yang potensial, dimana dari 72 metode terdapat 37 metode yang masih dalam investigasi dan sebanyak 35 metode telah diinvestigasi dan dapat digunakan dalam pengukuran Human Reliability dalam konteks Keselamatan dan Kesehatan Kerja serta Lingkungan Hidup (Bell dan Holyord, 20090 [8]. Human Error Assesment and Reduction Technique (HEART) sebagai metode HRA yang cepat dan sederhana dalam mengkualifikasikan risiko human error. Untuk mengukur Human Error Probability m enggunakan metode HEART. Adapun langkah-langkah perhitungannya adalah sebagai berikut :

1. Membuat hierarchy task analysis (HTA)

2. Penetuan Tipe Task Unreability Dari Kemungkinan Error Yang Terjadi berdasarkan tabel GTTs

3. Penentuan Kondisi Yang Menyebabkan Error Berdasarkan Error Producing Conditions (EPCs)

4. Penentuan Besar Nilai Assesed Proportion of Effect (APOE)

5. Perhitungan Nilai Assesed Effect (AEi)

6. Perhitungan Nilai Human Error Probability (HEP)

Power Plant merupakan stasiun yang menghasilkan tenaga listik yang sumbernya dari generator diesel dan turbin uap yang menggerakkan generator.Stasiun pembangkit listik adalah sumber tenaga yang diperlukan untuk menggerakkan mesin pada pengolahan. Dan juga sebagai tempat masuknya uap dari boiler ke setiap stasiun yang ada di PKS ( Naibaho,1996) [9]. Adapun tujuan yang dilakukan dalam penelitian ini adalah :

1. Mengidentifikasi aktivitas yang berpotensi terjadi human error.

2. Mengukur human error pada bagian engine room dengan metode HEART.

3. Memberikan rekomendasi perbaikan sistem kerja bagian engine room.

\section{Metodologi}

Pada penelitian diperlukan langkah-langkah yang merupakan rangkaian proses untuk menyelesaikan penelitian secara sistematis. Langkah-langkah yang dikerjakan sebagai berikut :

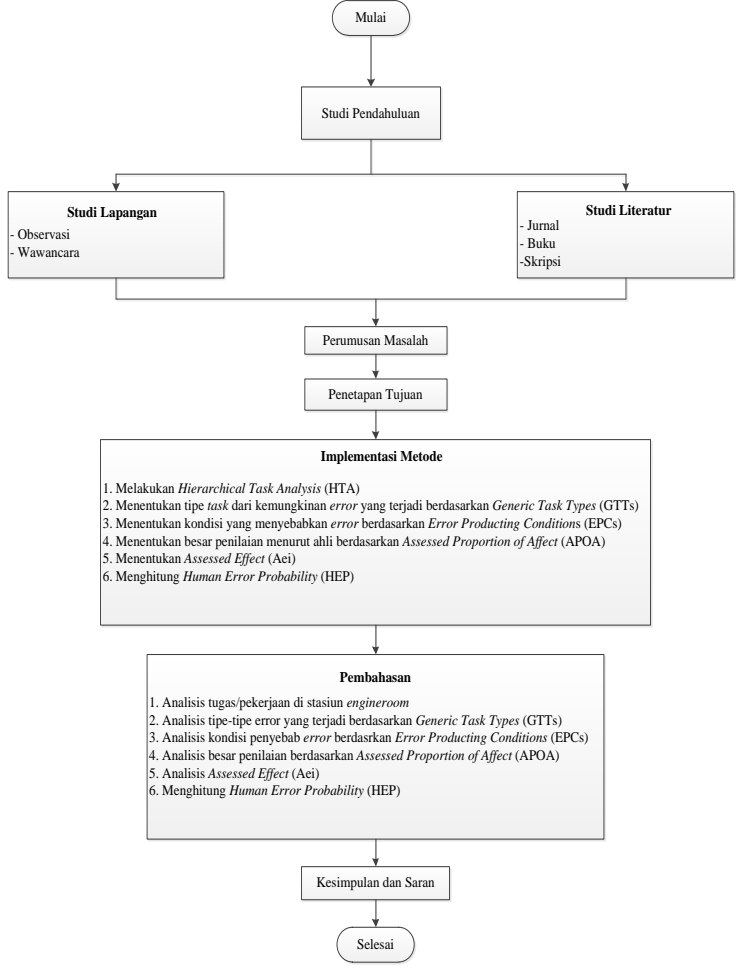

\section{Hasil Pembahasan}

Proses pekerjaan PT. Adei Plantation \& Industry oleh operator engine room dijabarkan secara mendetail. Operasi pekerjaan dilambangkan dengan lambing huruf. Adapun subtasknya dilambangkan dengan angka. Berikut identifikasi kegagalan pada pengoperasian mesin turbin dan genset :

Tabel 2. Keterangan HTA dan Identifikasi Kegagalan Pada Pengoperasian Mesin Turbin dan Genset

\begin{tabular}{|c|l|l|l|}
\hline \multicolumn{3}{|c|}{ Mesin Turbin } \\
\hline Step & \multicolumn{1}{|c|}{$\begin{array}{c}\text { Task } \\
\text { Description }\end{array}$} & $\begin{array}{c}\text { Identifikasi } \\
\text { Kegagalan }\end{array}$ & $\begin{array}{c}\text { Konsekuensi } \\
\text { Kegagalan }\end{array}$ \\
\hline 0 & Sebelum Pengoperasian & Kekurangan oli \\
\hline 1 & $\begin{array}{l}\text { Mengontrol } \\
\text { level oli }\end{array}$ & $\begin{array}{l}\text { Tidak akurat } \\
\text { melihat level oli }\end{array}$ & $\begin{array}{l}\text { Kebocoran Oli } \\
\text { oli }\end{array}$ \\
\hline 3 & $\begin{array}{l}\text { Pengoperasian } \\
\text { Turbin }\end{array}$ & $\begin{array}{l}\text { Gagal } \\
\text { mengoperasikan } \\
\text { mesin }\end{array}$ & Mesin mati \\
\hline $4 b$ & $\begin{array}{l}\text { Synkronisasi } \\
\text { beban }\end{array}$ & $\begin{array}{l}\text { Gagal } \\
\text { mensinkronisasi }\end{array}$ & Mesin trip \\
\hline
\end{tabular}




\begin{tabular}{|l|l|l|l|}
\hline \multicolumn{3}{|c|}{ Mesin Genset } \\
\hline Step & $\begin{array}{c}\text { Task } \\
\text { Description }\end{array}$ & \multicolumn{1}{|c|}{$\begin{array}{c}\text { Identifikasi } \\
\text { Kegagalan }\end{array}$} & $\begin{array}{c}\text { Konsekuensi } \\
\text { Kegagalan }\end{array}$ \\
\hline 0 & \multicolumn{3}{|c|}{ Sebelum Pengoperasian } \\
\hline 3 & $\begin{array}{l}\text { Mengontrol } \\
\text { bahan bakar }\end{array}$ & $\begin{array}{l}\text { Saringan bahan } \\
\text { bakar tersumbat }\end{array}$ & Mesin mati \\
\hline 4 & $\begin{array}{l}\text { Mengontrol } \\
\text { baterai Genset }\end{array}$ & $\begin{array}{l}\text { Kabel konektor } \\
\text { batrai longgar }\end{array}$ & Mesin mati \\
\hline 5 & $\begin{array}{l}\text { Pengoperasian } \\
\text { Genset }\end{array}$ & $\begin{array}{l}\text { Gagal } \\
\text { mengoperasikan } \\
\text { mesin }\end{array}$ & Mesin mati \\
\hline $5 \mathrm{a}$ & $\begin{array}{l}\text { Tekan tombol } \\
\text { "start" }\end{array}$ & $\begin{array}{l}\text { Memaksakan } \\
\text { menstarter } \\
\text { mesin }\end{array}$ & $\begin{array}{l}\text { Dynamo start } \\
\text { terbakar }\end{array}$ \\
\hline $5 \mathrm{~b}$ & $\begin{array}{l}\text { Tentukan } \\
\text { beban pada } \\
\text { generator }\end{array}$ & $\begin{array}{l}\text { Setting beban } \\
\text { tidak sesuai } \\
\text { dengan } \\
\text { kapasitas }\end{array}$ & Mesin mati \\
\hline $5 \mathrm{~g}$ & $\begin{array}{l}\text { Lakukan } \\
\text { paralel dengan } \\
\text { genset }\end{array}$ & $\begin{array}{l}\text { Beban tidak } \\
\text { sanggup } \\
\text { dipindahkan }\end{array}$ & Mesin trip \\
\hline
\end{tabular}

Selanjut Penentuan task unreability dari kemungkinan error yang terjadi dapat diklasifikasikan berdasarkan wawancara dengan narasumber (operator). Nilai nominal human unreability ditentukan berdasarkan tabel generic task types (GTTs).

Tabel 3. Penentuan Tipe Task Unreability dengan Generic Task Types (GTTs) Pada Mesin Turbin

\begin{tabular}{|c|c|c|c|}
\hline No & No. Task & $\begin{array}{c}\text { Tipe Generic } \\
\text { Task Types } \\
\text { (GTTs) }\end{array}$ & $\begin{array}{c}\text { Nilai Nominal } \\
\text { Human } \\
\text { Unreability }\end{array}$ \\
\hline 1 & 1 & D & 0,09 \\
\hline 2 & $1 \mathrm{c}$ & E & 0,02 \\
\hline 3 & 3 & C & 0,16 \\
\hline 4 & $4 \mathrm{~b}$ & D & 0,09 \\
\hline
\end{tabular}

Tabel 4. Penentuan Tipe Task Unreability dengan Generic Task Types (GTTs) Pada Mesin Genset

\begin{tabular}{|c|c|c|c|}
\hline No & $\begin{array}{c}\text { No. } \\
\text { Task }\end{array}$ & $\begin{array}{c}\text { Tipe Generic Task } \\
\text { Types (GTTs) }\end{array}$ & $\begin{array}{c}\text { Nilai Nominal } \\
\text { Human } \\
\text { Unreability }\end{array}$ \\
\hline 1 & 3 & G & 0,0004 \\
\hline 2 & 4 & G & 0,0004 \\
\hline 3 & 5 & C & 0,16 \\
\hline
\end{tabular}

\begin{tabular}{|c|c|c|c|}
4 & $5 \mathrm{a}$ & $\mathrm{E}$ & 0,02 \\
\hline 5 & $5 \mathrm{~b}$ & $\mathrm{D}$ & 0,09 \\
\hline 6 & $5 \mathrm{~g}$ & $\mathrm{D}$ & 0,09 \\
\hline
\end{tabular}

Tabel 5. Penentuan Kondisi Yang Menyebakan Error Berdasarkan Error Producing Conditions (EPCs) Pada Mesin Turbin

\begin{tabular}{|c|c|c|c|c|c|}
\hline $\begin{array}{l}\mathbf{N} \\
\mathbf{0}\end{array}$ & $\begin{array}{c}\text { No. } \\
\text { Tas } \\
\text { k }\end{array}$ & $\begin{array}{c}\text { Kemungkina } \\
\text { n Error }\end{array}$ & $\begin{array}{l}\text { No. } \\
\text { Tabe } \\
1 \\
\text { EPC } \\
\text { s }\end{array}$ & Deskripsi & $\begin{array}{l}\text { Nilai } \\
\text { EPC }\end{array}$ \\
\hline 1 & 1 & $\begin{array}{l}\text { Tidak akurat } \\
\text { melihat level } \\
\text { oli }\end{array}$ & 32 & $\begin{array}{l}\text { Inkonsistensi } \\
\text { makna antara } \\
\text { display dan } \\
\text { prosedur. }\end{array}$ & 1,2 \\
\hline 2 & $1 \mathrm{c}$ & $\begin{array}{l}\text { Posisi penutup } \\
\text { tidak sesuai }\end{array}$ & 17 & $\begin{array}{l}\text { Kurangnya } \\
\text { atau tidak } \\
\text { adanya } \\
\text { pengecekan } \\
\text { independen } \\
\text { atas pekerjaan } \\
\text { yang telah } \\
\text { dilakukan }\end{array}$ & 3 \\
\hline 3 & 3 & $\begin{array}{l}\text { Gagal } \\
\text { mengoperasika } \\
\mathrm{n} \text { mesin }\end{array}$ & 20 & $\begin{array}{l}\text { Ketidaksesuaia } \\
\mathrm{n} \text { antara } \\
\text { tingkat } \\
\text { pendidikan } \\
\text { yang } \\
\text { dibutuhkan } \\
\text { dengan tingkat } \\
\text { pekerjaan } \\
\text { yang diminta }\end{array}$ & 2 \\
\hline 4 & $4 b$ & $\begin{array}{l}\text { Gagal } \\
\text { mensinkronka } \\
\mathrm{n}\end{array}$ & 15 & $\begin{array}{l}\text { Kurangnya } \\
\text { pengalaman } \\
\text { operator }\end{array}$ & 3 \\
\hline
\end{tabular}

Tabel 6. Penentuan Kondisi Yang Menyebabkan Error Berdasrkan Error Producing Conditions (EPCs) Pada Mesin Genset

\begin{tabular}{|c|c|c|c|c|c|}
\hline $\begin{array}{l}\mathbf{N} \\
\mathbf{0}\end{array}$ & $\begin{array}{c}\text { No. } \\
\text { Tas } \\
\mathbf{k}\end{array}$ & $\begin{array}{l}\text { Kemungkin } \\
\text { an Error }\end{array}$ & $\begin{array}{l}\text { No. } \\
\text { Tabe } \\
\text { l } \\
\text { EPC } \\
\text { s }\end{array}$ & Deskripsi & $\begin{array}{c}\text { Nila } \\
\text { i } \\
\text { EP } \\
\text { C }\end{array}$ \\
\hline 1 & 3 & $\begin{array}{l}\text { Saringan bahan } \\
\text { bakar tersumbat }\end{array}$ & 17 & $\begin{array}{l}\text { Kurangnya } \\
\text { atau tidak } \\
\text { adanya } \\
\text { pengecekan } \\
\text { independen } \\
\text { atas pekerjaan } \\
\text { yang telah } \\
\text { dilakukan }\end{array}$ & 3 \\
\hline 2 & 4 & $\begin{array}{l}\text { Kabel konektor } \\
\text { batrai longgar }\end{array}$ & 17 & $\begin{array}{l}\text { Kurangnya } \\
\text { atau tidak } \\
\text { adanya } \\
\text { pengecekan } \\
\text { independen }\end{array}$ & 3 \\
\hline
\end{tabular}




\begin{tabular}{|c|c|c|c|c|c|}
\hline & & & & $\begin{array}{l}\text { atas pekerjaan } \\
\text { yang telah } \\
\text { dilakukan }\end{array}$ & \\
\hline 3 & 5 & $\begin{array}{l}\text { Gagal } \\
\text { mengoperasikan } \\
\text { mesin }\end{array}$ & 20 & $\begin{array}{l}\text { Ketidaksesuai } \\
\text { an antara } \\
\text { tingkat } \\
\text { pendidikan } \\
\text { yang } \\
\text { dibutuhkan } \\
\text { dengan } \\
\text { tingkat } \\
\text { pekerjaan } \\
\text { yang diminta }\end{array}$ & 2 \\
\hline 4 & $5 \mathrm{a}$ & $\begin{array}{l}\text { Memaksakan } \\
\text { menstarter } \\
\text { mesin }\end{array}$ & 12 & $\begin{array}{l}\text { Ketidaksesuai } \\
\text { an antara } \\
\text { risiko yang } \\
\text { dibayangkan } \\
\text { dengan risiko } \\
\text { sebenarnya. }\end{array}$ & 4 \\
\hline 5 & $5 b$ & $\begin{array}{l}\text { Setting beban } \\
\text { tidak sesuai } \\
\text { kapasitas }\end{array}$ & 12 & $\begin{array}{l}\text { Ketidaksesuai } \\
\text { an antara } \\
\text { risiko yang } \\
\text { dibayangkan } \\
\text { dengan risiko } \\
\text { sebenarnya. }\end{array}$ & 4 \\
\hline 6 & $5 \mathrm{~g}$ & $\begin{array}{l}\text { Beban tidak } \\
\text { sanggup } \\
\text { dipindahkan }\end{array}$ & 23 & $\begin{array}{l}\text { Ketidakandala } \\
\text { n dari } \\
\text { peralatan }\end{array}$ & 1,6 \\
\hline
\end{tabular}

Tabel 7. Penentuan Besar Nilai Assesed Proportion

\begin{tabular}{|c|c|c|}
\multicolumn{1}{c}{ of Effect (APOE) Pada Mesin Turbin } \\
\hline No & No. Task & Nilai Proportion of Effect \\
\hline 1 & 1 & 0,1 \\
\hline 2 & $1 \mathrm{c}$ & 0,5 \\
\hline 3 & 3 & 1 \\
\hline 4 & $4 \mathrm{~b}$ & 0,5 \\
\hline
\end{tabular}

Tabel 8. Penentuan Besar Nilai Assesed Proportion of Effect (APOE) Pada Mesin Genset

\begin{tabular}{|c|c|c|}
\hline No & No. Task & Nilai Proportion of Effect \\
\hline 1 & 3 & 0,2 \\
\hline 2 & 4 & 0,3 \\
\hline 3 & 5 & 1 \\
\hline 4 & $5 \mathrm{a}$ & 0,3 \\
\hline 5 & $5 \mathrm{~b}$ & 0,4 \\
\hline 6 & $5 \mathrm{~g}$ & 0,1 \\
\hline
\end{tabular}

Tabel 9. Hasil Perhitungan Nilai Assesed Effect (AEi) Pada Mesin Turbin

\begin{tabular}{|c|c|c|c|c|}
\hline No & $\begin{array}{c}\text { No. } \\
\text { Task }\end{array}$ & $\begin{array}{c}\text { Nilai Error } \\
\text { Producing } \\
\text { Conditions } \\
\text { (EpcS) }\end{array}$ & $\begin{array}{c}\text { Nilai } \\
\text { Assesed } \\
\text { Proportion } \\
\text { of Effect } \\
\text { (APOE) }\end{array}$ & $\begin{array}{c}\text { Nilai } \\
\text { Assesed } \\
\text { Effect (AEi) }\end{array}$ \\
\hline 1 & 1 & 1,2 & 0,1 & 1,02 \\
\hline 2 & $1 \mathrm{c}$ & 3 & 0,5 & 2 \\
\hline 3 & 3 & 2 & 1 & 2 \\
\hline 4 & $4 \mathrm{~b}$ & 3 & 0,5 & 1 \\
\hline
\end{tabular}

Tabel 10. Hasil Perhitungan Nilai Assesed Effect (AEi) Pada Mesin Genset

\begin{tabular}{|c|c|c|c|c|}
\hline No & $\begin{array}{c}\text { No. } \\
\text { Task }\end{array}$ & $\begin{array}{c}\text { Nilai Error } \\
\text { Producing } \\
\text { Conditions } \\
\text { (EpcS) }\end{array}$ & $\begin{array}{c}\text { Nilai } \\
\text { Assesed } \\
\text { Proportion } \\
\text { of Effect } \\
\text { (APOE) }\end{array}$ & $\begin{array}{c}\text { Nilai } \\
\text { Assesed } \\
\text { Effect (AEi) }\end{array}$ \\
\hline 1 & 3 & 3 & 0,2 & 1,4 \\
\hline 2 & 4 & 3 & 0,3 & 1,6 \\
\hline 3 & 5 & 2 & 1 & 2 \\
\hline 4 & $5 \mathrm{a}$ & 4 & 0,3 & 1,9 \\
\hline 5 & $5 \mathrm{~b}$ & 4 & 0,4 & 2,2 \\
\hline 6 & $5 \mathrm{~g}$ & 1,6 & 0,1 & 1,06 \\
\hline
\end{tabular}

Tabel 11. Hasil Perhitungan Nilai Human Error Probability (HEP) Pada Mesin Turbin

\begin{tabular}{|c|c|c|c|c|}
\hline No & $\begin{array}{c}\text { No. } \\
\text { Task }\end{array}$ & $\begin{array}{c}\text { Nominal } \\
\text { Human } \\
\text { Reliability }\end{array}$ & $\begin{array}{c}\text { Nilai } \\
\text { Assesed } \\
\text { Effect } \\
\text { (AEi) }\end{array}$ & $\begin{array}{c}\text { Nilai } \\
\text { Human } \\
\text { Error } \\
\text { Probability } \\
\text { (HEP) }\end{array}$ \\
\hline 1 & 1 & 0,09 & 1,02 & 0,3672 \\
\hline 2 & $1 \mathrm{c}$ & 0,02 & 2 & 0,0816 \\
\hline 3 & 3 & 0,16 & 2 & 0,6528 \\
\hline 4 & $4 \mathrm{~b}$ & 0,09 & 1 & 0,3672 \\
\hline
\end{tabular}

\section{Simpulan}

Berdasarkan hasil implementasi metode dan pembahasan, dapat disimpulkan bahwa :

1. Setelah diidentifikasi menggunakan Hierarchy Task Analysis (HTA) penyebab terjadinya listrik mati yang disebabkan oleh (human error) pada mesin turbin adalah mengontrol level oli, menutup penutup oli, pengoperasian turbin dan synkronisasi beban. Sedangkan untuk mesin genset kesalahan yang terjadi adalah mengontrol 
bahan bakar, mengontrol baterai genset, pengoperasian genset, tekan tombol "start", menentukan beban pada generator, dan melakukan paralel dengan genset.

2. Besarnya tingkat Human Error Probability (HEP) yang ada pada stasiun engine room di PT. Adei Plantation \& Industry, adalah pada saat pengoperasian mesin pembangkit yaitu pada mesin turbin memiliki probabilitas sebesar 0,6528. Sedangkan probabilitas (HEP) tertinggi pada mesin genset sebesar 3,1759.

3. Berdasarkan analisa bahwa operator tidak mematuhi SOP yang berlaku di enginer room dan dengan tindakan tersebut maka dapat direkomendasikan kepada perusahaan khususnya bagian stasiun engine room berupa standart operating procedure (SOP) dapat dilihat pada tabel 5.12 yang menjelaskan prosedur pada penggunaan APD, Operator dan Pengawas.

\section{Daftar Pustaka}

[1] Sanders, Mark S., Cormick, Ernest J. Human Factors In Engineering And

Design $7^{\text {th }}$ Edition. Mc Graw Hill. 1993

[2] Soesanto, I. A. Analisis Keandalan Karyawan dengan Metode Simplified

Cognitive Reliability Error Assesment Method

Di PT. Adi Satria Abadi. Yogyakarta. Skripsi
Program Studi Teknik Industri Universitas Atma Jaya. 2010

[3] Wahyu, Erwin. Hubungan Antara Perilaku Pekerja Dengan Kejadian Kecelakaan Kerja Bagian Produksi PT. Linggarjati Mahardika Mulia Pacitan. Semarang. Skripsi Universitas Negeri Semarang. 2015: 110-115

[4] Winarsunu, Tulus. Psikologi Kesalamatan Kerja. Malang. UMM Press. 2008

[5] Dhillon, B. S. Reliability, Quality, and Safety Engineering. CRS Press. 2005

[6] Birolini, Springer. Reliability Engineering: Theory and Pratice-Eight. ISBN 978-3-662-54208-8. 2017

[7] Hollnagel, E. Human Reliabillity Assesment in Context. Nuclear Engineering and Technology 2005, 37 (2) : 159-166.

[8] Naibaho, Ponten. Teknologi Pengolahan Hasil Perkebunan. Medan. 1996

[9] Sanders. Human Error. Canada : Department of Mechanical Engineering, University o Ottawa.1993

[10] Meister, D. Human Engineering Data Base for Design and Selection of Cathode Ray Tube and Other Display Systems. Retrieved From. 1984 